\title{
STRONGLY $\lambda$-CONVEX FUNCTIONS AND SOME CHARACTERIZATION OF INNER PRODUCT SPACES
}

\author{
MirosŁaW ADAMEK
}

Abstract. In this paper we show that each strongly $\lambda$-convex function $f: D \rightarrow \mathbb{R}$ with modulus $c>0$, where $D$ is an nonempty convex subset of inner product space $X$ with norm $\|\cdot\|$, must by of the form $g+\|\cdot\|^{2}$, where $g$ is an $\lambda$-convex function. Moreover, involving the notion of strongly $\lambda$-convexity we get a new characterization of inner product space.

Mathematics subject classification (2010): Primary 46C15, Secondary 26B25, $39 \mathrm{~B} 62$.

Keywords and phrases: Strongly convex function, strongly $\lambda$-convex function, inner product space.

\section{REFERENCES}

[1] J. Aczél And J. Dhombres, Functional equations in several variables, Encyclopaedia of Mathemathics and its Applications, Cambridge University Press, Cambridge, 1989.

[2] M. AdAmeK, On $\lambda$-quasiconvex and $\lambda$-convex functions, Radovi Matematički 11 (2003), 1-11.

[3] A. Aleman, On some generalizations of convex sets and convex functions, Anal. Numér. Théor. Approx., 14, 1 (1985), 17-48.

[4] J. Alfonso, Some remarks on inequalities that characterize inner product spaces, Internat. J. Math. Math. Sci. 15 (1) (1992), 31-34.

[5] C. Alsina, P. CRUells AND M. S. TomÁs, Characterizations of inner product spaces through an isosceles trapezoid property, Arch. Math. (Brno) 35 (1992), 21-27.

[6] C. Alsina, J. SiKORSKA AND M. S. TOMÁs, Norm derivatives and characterizations of inner product spaces, Hackensack, NJ: World Scientific, 2010.

[7] D. AMIR, Characterizations of inner product spaces, Operator Theory: Advances and Applications, 20., Birkhäuser, Basel-Boston-Stuttgart, 1986.

[8] F. Dadipour And M. S. Moslehian, A characterization of inner product spaces related to the p-angular distance, J. Math. Anal. Appl. 371 (2010), no. 2, 677-681.

[9] J.-B. HiRiart-URRUTY AND C. LemaréChal, Fundamentals of Convex Analysis, Springer-Verlag, Berlin-Heidelberg, 2001.

[10] P. Jordan AND J. von Neumann, On inner products in linear metric spaces, Ann. Math. 36 (1935), $719-723$.

[11] K. Nikodem, Zs. PÁLES, Characterizations of inner product spaces by strongly convex functions, Banach J. Math. Anal. 5 (2011), no. 1, 83-87.

[12] Zs. PÁLES, Bernstein-Doetsch type results for general functional inequalities, Rocznik Nauk.-Dydakt. Akad. Pedagog. w Krakowie 204 Prace Mat. 17 (2000), 197-206.

[13] B. T. POLYAK, Existence theorems and convergence of minimizing sequences in extremum problems with restrictions, Soviet Math. Dokl. 7 (1966), 72-75.

[14] A. W. Roberts and D. E. Varberg, Convex Functions, Academic Press, New York-London, 1973.

[15] J.-P. VIAL, Strong convexity of sets and functions, J. Math. Economics 9 (1982), 187-205. 